\title{
Modulación de las respuestas fisiológicas ante estímulos afectivos: una herramienta para investigar procesos psicológicos*
}

Modulation of Physiological Response to Affective Stimuli: A Tool for Psychological Processes Assessment

Recepción: 10 Noviembre 2016 | Aceptación: 04 Julio 2017

\author{
Carlos Gantiva $^{\mathrm{a}}$ \\ Universidad de San Buenaventura, Colombia \\ ORCID: http://orcid.org/0000-0002-9232-121X \\ María Casas \\ Universidad de San Buenaventura, Colombia \\ YERALDín BALLÉN \\ Universidad de San Buenaventura, Colombia \\ Miguel Sotaquirá \\ Universidad de San Buenaventura, Colombia \\ ORCID: http://orcid.org/0000-0002-7914-284X \\ TAnia Romo-GonzÁlez \\ Universidad Veracruzana, México \\ ORCID: http://orcid.org/0000-0003-0097-4780
}

a Autor de correspondencia. Correo electrónico: cgantiva@gmail.com
Para citar este artículo: Gantiva, C., Casas, M., Ballén, Y., Sotaquirá, M., \& Romo-González, T. (2019). Modulación de las respuestas fisiológicas ante estímulos afectivos: una herramienta para investigar procesos psicológicos. Universitas Psychologica, 18(1), 1-12.https://doi.org/10.11144/Javeriana.upsy18-1.mrfe

\section{RESUMEN}

El estudio de los procesos psicológicos suele realizarse a partir de medidas de autorreporte y, en algunos casos, a través de tareas conductuales. Sin embargo, cada vez es más necesario obtener medidas más precisas y objetivas de las respuestas psicológicas para fortalecer las conclusiones de los estudios y su alcance. Por lo anterior, el objetivo del presente estudio fue analizar los cambios en distintas respuestas fisiológicas ante estímulos con diferente contenido afectivo, para obtener indicadores fisiológicos de los procesos atencionales, emocionales y motivacionales. Se registraron las respuestas de 40 participantes mientras observaban estímulos apetitivos, neutrales y aversivos. Los resultados muestran que los estímulos apetitivos y aversivos generan mayor respuesta de conductividad de la piel, lo que indica mayor activación simpática y mayor respuesta de orientación, así como mayor desaceleración de la tasa cardiaca y mayor inhibición prepulso, lo que sugiere una mayor respuesta atencional. También se encontró que los estímulos aversivos potencian el reflejo de sobresalto y los apetitivos lo inhiben, lo que lo convierte en un marcador fisiológico de la respuesta motivacional. No se encontraron diferencias significativas entre hombres y mujeres. En conjunto, los resultados apoyan el uso de estas metodologías para el estudio de la orientación/atención, la emoción y la motivación.

Palabras clave

orientación; atención; emoción; motivación; psicofisiología. 


\section{ABSTRACT}

Conventional tools for the assessment of psychological processes rely on the use of self-report questionnaires and behavioral tasks, in spite of the existence of objective and more accurate physiological responses that could provide new insights into such processes. Accordingly, the aim of this study was to analyze the changes in different physiological responses to stimuli with different affective content, to obtain physiological indicators of the attentional, emotional and motivational processes. The responses of 40 participants were recorded while observing pleasant, neutral and unpleasant stimuli. Results show that the pleasant and unpleasant stimuli generate a greater galvanic skin response, which indicates a greater sympathetic activation and a greater orientation response, as well as a greater heart rate deceleration and greater prepulse inhibition, which suggests a greater attentional response. It was also found that unpleasant stimuli enhance the startle reflex and the pleasant stimuli inhibit it, making it a physiological marker of motivational response. There were no significant differences between men and women. Overall, the results support the use of these methodologies for the study of orientation/attention, emotion and motivation.

Keywords

orientation; attention; emotion; motivation; psychophysiology.

Las respuestas atencionales, emocionales y motivacionales se integran coherentemente en el modelo bio-informacional, el cual establece que las emociones son predisposiciones para la acción a partir de la activación de uno de los dos sistemas motivacionales primarios (Lang, 1995). Desde una perspectiva evolucionista, la función de la emoción es facilitar la adaptación del organismo a las demandas del contexto asegurando su supervivencia (Bradley, 2009; Lang, Davis, \& Öhman, 2000). El modelo bio-informacional ha demostrado que las emociones están compuestas por respuestas fisiológicas, conductuales y cognitivas y están estructuradas en tres niveles jerárquicos (Bradley \& Lang, 2007). En el nivel básico, están las respuestas específicas (fisiológicas, conductuales y cognitivas) que dependen del contexto, en el nivel intermedio, se encuentran las subrutinas que integran las respuestas específicas y es donde están las emociones (miedo, ansiedad, alegría, entre otras) y, en el nivel superior, están las dimensiones de valencia, arousal y dominancia, que son las que componen todas las emociones y permiten su estudio de forma objetiva (Lang, 1995).

La valencia es la dimensión principal sobre la cual se estructura la experiencia emocional, $\mathrm{y}$ hace referencia al sistema motivacional que se activa, apetitivo o defensivo, lo que genera conductas de aproximación o evitación, respectivamente. Tiene un sustrato neurofisiológico específico el cual se activa de forma aditiva para determinar la valencia final de la emoción (Gantiva, Guerra, \& Vila, 2011). El arousal es la intensidad de la respuesta emocional, hace referencia a la energía invertida durante la emoción, y se ha demostrado que aumenta tanto por la activación del sistema motivacional apetitivo como por el defensivo (Gantiva \& Camacho, 2016). La dominancia es la dimensión más reciente a nivel evolutivo, ubicándose en la corteza prefrontal hace referencia al grado de control que se experimenta sobre la respuesta emocional, y permite la interrupción o continuidad de la respuesta conductual (Bradley \& Lang, 2007).

El estudio de las dimensiones de la emoción utilizando medidas de autorreporte, como el Self-Assessment Manikin (SAM) (Bradley \& Lang, 1994), muestra sistemáticamente que los estímulos se distribuyen en el espacio afectivo bidimensional compuesto por valencia y arousal en forma de bumerán, donde los estímulos que puntúan con una valencia apetitiva o aversiva también lo hacen con altos niveles de arousal (Bradley, Codispoti, Cuthbert, \& Lang, 2001; Lang, 1995; Gantiva et al., 2011). También se ha identificado que los puntajes en dominancia varían con respecto al nivel de arousal, siendo menor ante estímulos con valencia aversiva y alto arousal (Gantiva, Rodríguez, Arias, \& Rubio, 2012). Bajo esta metodología, se han estudiado fenómenos tan relevantes como las adicciones (Gantiva, Delgado, \& Romo-González, 2015; Muñoz et al., 2013), la agresividad (Gantiva et al., 2014) y los trastornos de la conducta alimenticia (Micoli et al., 2014), entre otros. Los resultados de todos los estudios reflejan la eficiencia de esta metodología para la comprensión de las emociones y la motivación en estas problemáticas; sin embargo, aunque 
es una metodología con respaldo cuantitativo y psicométrico (Bradley \& Lang, 1994), sigue siendo una estrategia basada en el autorreporte de los participantes.

Un avance significativo en el estudio de las emociones, la atención y la motivación ha sido el uso de medidas objetivas (p. ej., medidas fisiológicas), las cuales han permitido hacer estudios más precisos al medir las respuestas básicas asociadas a procesos psicológicos y evitar sesgos de deseabilidad social. Las investigaciones que utilizan respuestas del sistema nervioso periférico para el estudio de la emoción, la atención y la motivación han demostrado que el registro de la electromiografía de músculos faciales, la respuesta de conductividad de la piel (RCP) y la tasa cardiaca, entre otros, son medidas objetivas de la valencia, el arousal y la atención (Bradley et al., 2001).

La modulación del reflejo de sobresalto a partir del registro de la electromiografía del músculo orbicular utilizando el paradigma de visualización de imágenes afectivas, ha mostrado ser un indicador confiable de la valencia de la respuesta emocional/motivacional (Bradley \& Lang, 2007; Gantiva, Guerra, \& Vila, 2015; Lang, 1995) y de atención (Bradley, Codispoti, \& Lang, 2006; Bradley, Cuthbert, \& Lang, 1993). El reflejo de sobresalto es generado por la percepción de un estímulo sorpresivo y aversivo (p. ej., sonido intenso) que genera un reflejo defensivo cuyo componente más confiable es el parpadeo (Bradley \& Lang, 2007). La modulación afectiva del reflejo de sobresalto se presenta cuando el sonido que genera el reflejo se presenta después de aproximadamente tres segundos de iniciada la imagen, cuando esta es aversiva se potencia y cuando es apetitiva se inhibe (Lang, 1995). Este fenómeno ocurre, en el caso de las imágenes aversivas, porque la valencia es coherente con la valencia del estímulo sonoro que genera el sobresalto y, en el caso de las imágenes apetitivas, porque las valencias son diferentes.

La modulación atencional del reflejo de sobresalto se presenta cuando el sonido que genera el sobresalto ocurre a los pocos milisegundos de aparición de la imagen (p. ej., entre los 150 y $300 \mathrm{~ms}$ ). Los estudios muestran que el reflejo de sobresalto se inhibe ante imágenes apetitivas y aversivas y se potencia ante las neutrales (Bradley et al., 1993). A este fenómeno se le conoce como inhibición prepulso y es un indicador confiable de atención (Bradley et al., 2006), ya que los recursos atencionales son consumidos por las imágenes apetitivas y aversivas, dejando pocos recursos para el sonido de sobresalto, lo que genera su inhibición; por el contrario, las imágenes neutrales al no capturar la atención dejan muchos recursos para los demás estímulos, entre ellos, el sonido que genera el sobresalto, lo que hace que se potencie (Bradley et al., 2006).

La RCP es un indicador confiable de arousal, y por lo tanto de la activación del sistema nervioso simpático; corresponde a una respuesta autónoma que inicia aproximadamente después de los dos segundos de iniciado el estímulo y se cuantifica a partir de la amplitud de la respuesta (Bradley \& Lang, 2007). Se ha encontrado mayor RCP ante estímulos con valencia apetitiva y aversiva y menor ante estímulos neutrales (Bradley et al., 2001).

Los cambios en la tasa cardiaca después de la presentación de un estímulo han mostrado ser indicadores de diferentes respuestas psicológicas. Por ejemplo, la desaceleración inicial que se presenta durante los tres primeros segundos de iniciado un estímulo (p. ej., una imagen), ha demostrado ser un indicador confiable de atención (Bradley et al., 2001). Los estudios muestran que aparece una mayor desaceleración de la tasa cardiaca ante estímulos aversivos, seguida por la desaceleración ante estímulos apetitivos, y una menor desaceleración ante estímulos neutrales, debido a que los estímulos aversivos generan mayor atención por parte del observador debido a la posibilidad de que ocurra una amenaza real (Bradley, 2009; Gantiva, Araujo, Aragão, \& Hewitt, 2017). La desaceleración sostenida de la tasa cardiaca es la reacción más común ante estímulos amenazantes en animales (i. e. bradicardia del miedo). Esto ocurre cuando se está expuesto a un contexto amenazante, por ejemplo, donde el predador está cerca. De acuerdo al modelo de la cascada de defensa (Bradley \& Lang, 2007), la 
desaceleración de la tasa cardiaca es un indicador de atención hacia un estímulo amenazante que ocurre cuando hay una activación moderada del sistema motivacional defensivo, pero la acción no es inminente. En el paradigma de visualización de imágenes afectivas, las imágenes aversivas generan un contexto amenazante por lo cual ocurre la desaceleración. Solo se ha observado aceleración de la tasa cardiaca en este tipo de estudios cuando las imágenes corresponden, por ejemplo, a estímulos fóbicos (Hamm, Cuthbert, Globisch, \& Vaitl, 1997).

A pesar de la relevancia de estas metodologías para el estudio de la atención, la emoción y la motivación, desde nuestro conocimiento no existen estudios en población latinoamericana que describan los procedimientos, resultados e implicaciones de las respuestas psicofisiológicas ante estímulos con diferente contenido afectivo que permitan, posteriormente, utilizarlos para el estudio de conductas funcionales $\mathrm{O}$ disfuncionales. Por lo anterior, el objetivo del presente estudio fue analizar las respuestas psicofisiológicas (i. e. inhibición prepulso, modulación afectiva del reflejo de sobresalto, respuesta de conductividad de la piel y tasa cardiaca) ante imágenes apetitivas, neutrales y aversivas, e identificar las posibles diferencias entre hombres y mujeres.

\section{Método}

\section{Participantes}

Para determinar el tamaño mínimo de la muestra, se llevó a cabo un análisis de poder con el software $G^{*}$ Power 3 (Faul, Erdfelder, Lang, \& Buchner, 2007), utilizando un $\alpha=0.05,1-\beta=0.8$ y un tamaño del efecto $=0.25$ (Cohen, 1988). A partir de los resultados, se seleccionaron 40 estudiantes universitarios, con un rango de edad entre 20 y 27 años. Los participantes estaban conformados por 20 mujeres (20-26 años, $\mathrm{M}=22.16, \mathrm{DE}=3.67)$ y 20 hombres $(20-27$ años, $M=23.76, D E=3.83)$. No hubo diferencias significativas entre las edades de cada grupo $\left(t_{31}=0.14, p=0.67\right)$. Como criterios de exclusión al estudio, se tuvo en cuenta el reporte de enfermedades físicas o psicológicas, estar bajo tratamiento farmacológico y tener problemas de visión o audición no corregidos. Todos los participantes firmaron el formato de consentimiento informado.

\section{Estímulos}

Se seleccionaron 36 imágenes (12 apetitivas, 12 neutrales y 12 aversivas) del Sistema Internacional de Imágenes Afectivas (IAPS) ${ }^{1}$ (Lang, Bradley, \& Cuthbert, 2008) a partir de los valores normativos de la población colombiana (Gantiva et al., 2011). Los valores promedio en valencia de las imágenes apetitivas fueron 7.06 $(D E=0.39)$, de las neutrales $5.9(D E=0.18)$ y de las aversivas $2.38(D E=0.65)$ (la diferencia fue significativa entre todas las categorías de imágenes, todas las $p<0.001)$. Para la dimensión de arousal los puntajes de las imágenes apetitivas fueron $6.72(D E=0.6)$, de las neutrales 3.59 $(D E=0.23)$ y de las aversivas $6.40(D E=0.3)$ (la diferencia fue significativa entre las imágenes afectivas y las imágenes neutrales, ambas $p<$ 0.001).

\section{Procedimiento}

Cada imagen se presentó dos veces, para un total de 72 ensayos. Se organizaron tres órdenes diferentes de presentación de los estímulos, con la restricción de no presentar dos veces seguidas una imagen de la misma categoría. Las imágenes fueron presentadas durante 6 segundos en una pantalla plana de 19 pulgadas localizada aproximadamente a 60 centímetros del participante. El intervalo entre ensayos (IEE) varió aleatoriamente entre 10 y 14 segundos. El estímulo para generar el reflejo de sobresalto consistió en un ruido blanco de $50 \mathrm{~ms}$ de duración, de $105 \mathrm{~dB}$ y de tiempo de subida instantáneo. El sonido de sobresalto se presentó en ocho imágenes por cada categoría entre los $250 \mathrm{~ms}$ y $300 \mathrm{~ms}$ después de iniciar la imagen (24 ensayos con sobresalto para generar 
inhibición prepulso) y en ocho imágenes por cada categoría entre los 4000 ms y 5500 ms después de iniciar la imagen (24 ensayos con sobresalto para generar modulación afectiva) (Blumenthal et al., 2005). Adicionalmente, se presentó el sonido de sobresalto durante cuatro IEE para evitar su predicción. Las imágenes y el sonido de sobresalto se programaron en el software E-Prime 2.0 (Psychology Software Tools, PA, USA).

\section{Medidas fisiológicas}

La electromiografía (EMG) del músculo orbicular, el pulso y la conductividad de la piel se registraron con un equipo PowerLab 26T (ADInstruments, Australia). La EMG se registró a través de dos electrodos de $4 \mathrm{~mm}$ de $\mathrm{Ag} / \mathrm{AgCl}$ colocados en el músculo orbicular del ojo izquierdo (Blumenthal et al., 2005). La EMG fue registrada utilizando filtros de banda de frecuencia de $10-500 \mathrm{~Hz}$. La señal fue rectificada e integrada con una constante de tiempo de $20 \mathrm{~ms}$. El pulso digital fue registrado con un plestimógrafo ubicado en la falange distal del dígito II de la mano dominante. La tasa cardiaca fue identificada a través de un algoritmo específico para pulso digital en el software LabChart 7.3 (ADInstruments, Australia). La conductividad de la piel fue registrada con dos electrodos de $\mathrm{Ag} / \mathrm{AgCl}$ colocados en las falanges intermedias de los dedos II y IV de la mano no dominante. La señal fue calibrada antes de cada sesión para detectar cualquier actividad entre $0.40 \mu \mathrm{S}$ (microSiemens). Se utilizó un amplificador ML116 GSRAmp (ADInstruments, Australia). Todas las señales fueron registradas con una tasa de muestreo de $1000 \mathrm{~Hz}$.

\section{Cuantificación de los datos}

La amplitud del reflejo de sobresalto se definió como la diferencia entre la máxima actividad del EMG entre los 20-150 ms después del sonido menos el promedio de los $25 \mathrm{~ms}$ de la actividad del EMG antes del sonido (Blumenthal et al., 2005). Para corregir la variabilidad individual en la amplitud del reflejo de sobresalto, la magnitud de la respuesta se transformó a puntuaciones T en cada sujeto. El $3.6 \%$ de los ensayos con sobresalto se eliminaron debido a inestabilidad en la línea de base ( $>2 \mathrm{DE}$ por encima de la media de cada sujeto).

La respuesta de conductividad de la piel (RCP) y la desaceleración de la tasa cardiaca se determinaron substrayendo la actividad del segundo previo a la presentación de la imagen de la actividad de cada $500 \mathrm{~ms}$ durante el tiempo de presentación. La RCP se determinó a partir del máximo cambio ocurrido entre el segundo 1 al 4 después de la presentación del estímulo, posteriormente, a este valor se le realizó una transformación logarítmica (log [RCP + 1]) para la normalización de los datos. Para determinar el pico de desaceleración de la tasa cardiaca como indicador de una respuesta de atención y orientación, se identificó la máxima desaceleración en los primeros 3 segundos de presentación de cada imagen (Bradley et al., 2001). Para la evaluación de la RCP y la desaceleración de la tasa cardiaca, solo se tomaron en cuenta los ensayos en donde no se presentó el sonido de sobresalto para generar la respuesta de inhibición prepulso.

\section{Medidas de autorreporte}

Para la evaluación subjetiva de las dimensiones de la emoción se utilizó el Maniquí de autoevaluación (Self-Assessment Manikin [SAM]). El SAM es un instrumento desarrollado por Bradley y Lang (1994), compuesto por tres escalas (valencia, arousal y dominancia). Cada dimensión se mide a través de cinco figuras humanoides que indican diferentes niveles de intensidad (desde 1, que indica el nivel más bajo, hasta 9, que indica el máximo nivel). Adicionalmente, se pueden marcar niveles intermedios entre cada figura. El SAM ha mostrado niveles apropiados de validez en población colombiana para cada una de las dimensiones (0.79 a 0.97) (Gantiva et al., 2011). 


\section{Análisis estadístico}

Para analizar el impacto de la valencia de las imágenes y el sexo de los participantes sobre las respuestas fisiológicas y las medidas de autorreporte, se llevaron a cabo ANOVA mixtas 2 $\times 3$ de medidas repetidas, con Sexo (mujeres/ hombres) como factor intersujeto e Imagen (apetitivas, neutrales y aversivas) como factor intrasujeto. Se aplicó el factor de corrección Greenhouse-Geisser en los grados de libertad para corregir posibles violaciones a la esfericidad. La comparación de pares post hoc se llevó a cabo con la corrección Bonferroni. El nivel de significancia para todos los análisis fue de $0.05 \mathrm{y}$

se reporta el tamaño del efecto $\left(\eta_{\mathrm{p}}{ }^{2}\right)$, tomando como puntos de corte $0.01=$ pequeño, $0.06=$ medio y 0.14 = grande (Cohen, 1988; Richardson, 2011). Todos los análisis estadísticos se realizaron con el software SPSS 20.0.

\section{Resultados}

Respuesta de conductividad de la piel (RCP

El ANOVA para la RCP identificó un efecto principal significativo para Imagen $(F$ 2,68 $=$

5.24, $p=0.01, \eta_{\mathrm{p}}{ }^{2}=0.13$ ). Las imágenes apetitivas y aversivas generaron mayor RCP que las imágenes neutrales (ambas $\mathrm{p}<0.015$ ) (Figura 1), lo que indica mayor activación del sistema nervioso simpático y mayor orientación ante las imágenes afectivas en comparación con las imágenes neutrales. La tendencia cuadrática entre las imágenes fue significativa y con un tamaño del efecto grande $\left(F_{1,34}=18.56, p<\right.$

$\left.0.0001, \eta_{\mathrm{p}}{ }^{2}=0.35\right)$. No se encontró ningún otro efecto principal o de interacción significativos.
Figura 1

Respuesta de conductividad de la piel ante diferentes tipos de estímulos.

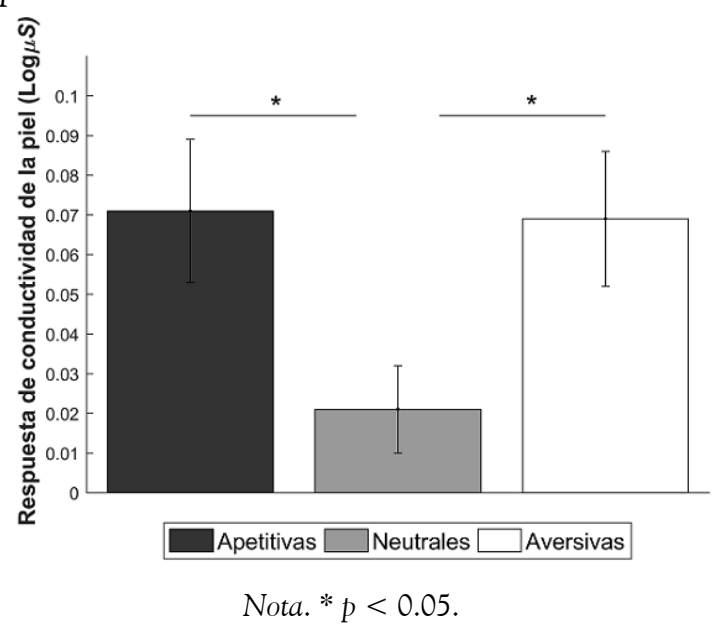

Inhibición prepulso del reflejo de sobresalto

El ANOVA para la inhibición prepulso del reflejo de sobresalto identificó un efecto principal significativo para Imagen $\left(F_{2,60}=7.57, p=\right.$ $0.001, \eta_{\mathrm{p}}{ }^{2}=0.2$ ). Las imágenes apetitivas y aversivas inhibieron el reflejo de sobresalto en comparación con las imágenes neutrales (ambas $p<0.02$ ) (Figura 2), lo que sugiere una mayor respuesta atencional ante las imágenes afectivas en comparación con las neutrales. Una fuerte y significativa tendencia cuadrática se encontró entre las imágenes $\left(F_{1,30}=15.7, p<0.001, \eta_{\mathrm{p}}\right.$ $2=0.34)$. No se encontró ningún otro efecto principal o de interacción significativo. 
Figura 2

Inhibición prepulso ante estímulos con diferente contenido afectivo.

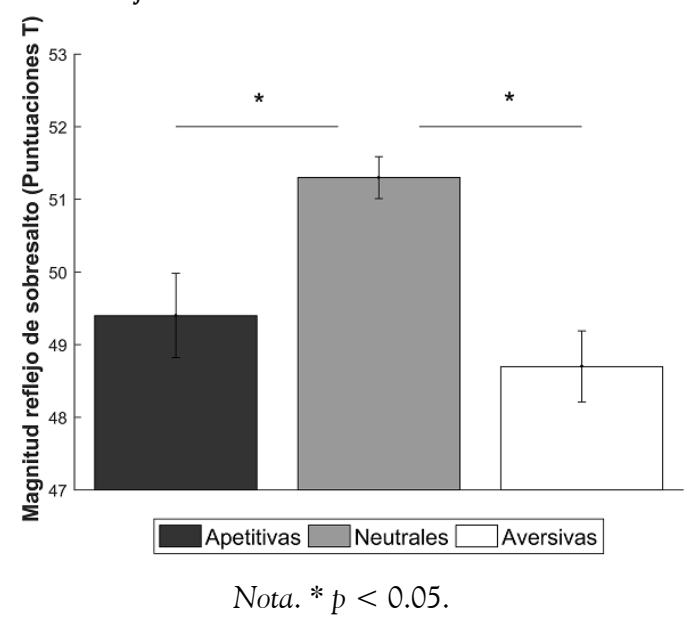

Tasa cardiaca

El ANOVA para la respuesta de la tasa cardiaca encontró un efecto principal significativo para Imagen $\left(F_{2,72}=3.76, p=0.03, \eta_{p}^{2}=0.09\right)$. Las imágenes apetitivas y aversivas generaron mayor desaceleración inicial de la tasa cardiaca en comparación con las imágenes neutrales (ambas $p<0.03$ ) (Figura 3). Nuevamente, esto sugiere una mayor respuesta atencional ante las imágenes afectivas en comparación con las neutrales. Se identificó una tendencia cuadrática significativa entre las imágenes con un tamaño del efecto grande $\left(F_{1,36}=12.18, p=0.001, \eta_{p}\right.$ $2=0.25)$. No se encontró ningún otro efecto principal o de interacción significativos.
Figura 3

Desaceleración de la tasa cardiaca ante estímulos con diferente contenido afectivo.

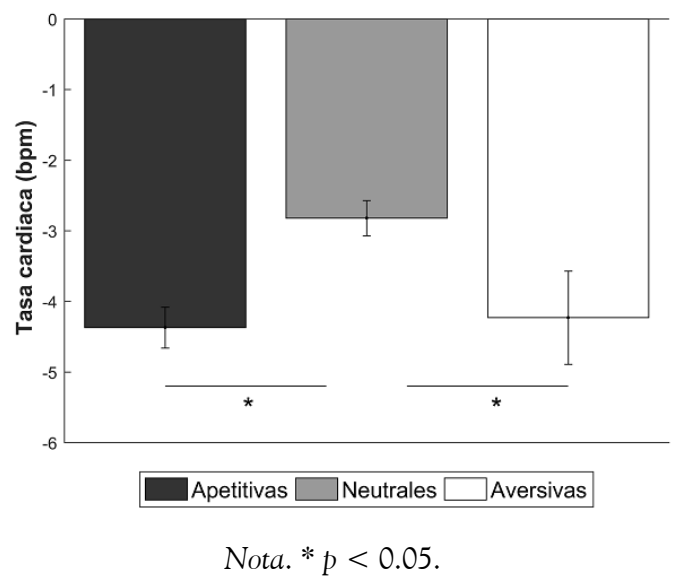

Modulación afectiva del reflejo de sobresalto

El ANOVA para la modulación afectiva del reflejo de sobresalto identificó un efecto principal significativo para Imagen $\left(F_{2,74}=7.34\right.$, $\left.p=0.001, \eta_{p}^{2}=0.16\right)$. Las imágenes aversivas potenciaron el reflejo de sobresalto en comparación con las imágenes apetitivas $(p=0.002)$. Se encontró una diferencia marginalmente significativa entre las imágenes apetitivas y neutrales $(p=0.07)$ (Figura 4). Estos resultados sugieren la activación del sistema motivacional defensivo ante las imágenes aversivas y del apetitivo ante las imágenes agradables. La tendencia lineal entre las imágenes fue significativa y con un tamaño del efecto grande $\left(F_{1,37}=14, p=0.001, \eta_{p}{ }^{2}=0.27\right)$. No se encontró ningún otro efecto principal o de interacción significativos. 


\section{Figura 4}

Modulación afectiva del reflejo de sobresalto ante estímulos con diferente contenido afectivo.

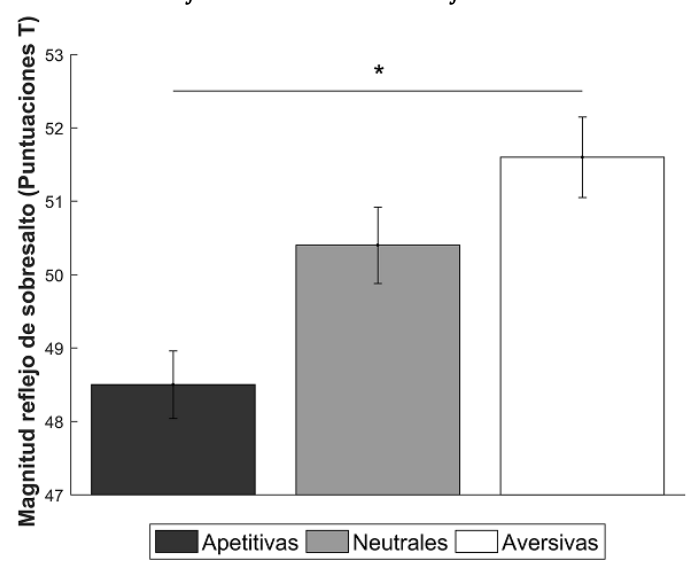

Nota. $* p<0.05$

\section{Medidas subjetivas}

El ANOVA para la dimensión de valencia encontró un efecto principal significativo para Imagen $(F \quad 2,72=175.65, p<0.0001$, $\left.\eta_{\mathrm{p}}{ }^{2}=0.83\right)$. Como era de esperarse, las imágenes apetitivas tuvieron mayores puntajes en valencia y las aversivas, menores; se encontraron diferencias entre todas las categorías de imágenes (todas las $p<0.001$ ). Se encontró una tendencia lineal fuerte y significativa entre las imágenes $\left(F_{1,36}=271.04, p<0.0001, \eta_{p}{ }^{2}=0.88\right) . \mathrm{El}$ ANOVA para la dimensión de arousal también identificó un efecto principal significativo para Imagen $\left(F_{2,72}=33.13, p<0.001, \eta_{p}{ }^{2}=0.47\right)$. Las imágenes apetitivas y aversivas tuvieron mayores puntajes en arousal que las imágenes neutrales (ambas $p<0.001$ ). La tendencia cuadrática entre las imágenes fue significativa y con un tamaño del efecto grande $\left(F_{1,36}=65.09\right.$, $\left.p<0.0001, \eta_{\mathrm{p}}{ }^{2}=0.64\right)$. Finalmente, el ANOVA para la dimensión de dominancia encontró nuevamente un efecto principal significativo para Imagen $\left(F_{2,72}=27.32, p<0.0001, \eta_{p}{ }^{2}\right.$ $=0.43)$. Las imágenes neutrales tuvieron los mayores puntajes en dominancia, seguidas por las imágenes apetitivas y las aversivas (todas las $p$ $<0.005)$. Una fuerte y significativa tendencia cuadrática se encontró entre las imágenes $\left(F_{1,36}\right.$ $=34.69, p<0.0001, \eta_{\mathrm{p}}{ }^{2}=0.49$ ) (Tabla 1$)$.

Tabla 1

Puntajes en el SAM para cada categoría de imágenes

\begin{tabular}{ccccccc}
\hline & \multicolumn{2}{c}{ Valencia } & \multicolumn{2}{c}{ Arousal } & \multicolumn{2}{c}{ Dominancia } \\
\cline { 2 - 7 } & $M$ & $D E$ & $M$ & $D E$ & $M$ & $D E$ \\
\hline Apetitiva & $6.89^{\mathrm{b}, \mathrm{c}}$ & 1.33 & $5.3^{\mathrm{b}}$ & 1.93 & $7.11^{\mathrm{b}, \mathrm{c}}$ & 1.39 \\
Neutral & $4.86^{\mathrm{a}, \mathrm{c}}$ & 1.27 & $2.6^{\mathrm{a}, \mathrm{c}}$ & 1.47 & $7.84^{\mathrm{a}, \mathrm{c}}$ & 1.29 \\
Aversiva & $2.32^{\mathrm{a}, \mathrm{b}}$ & 1.16 & $4.69^{\mathrm{b}}$ & 2.19 & $5.69^{\mathrm{a}, \mathrm{b}}$ & 2.05 \\
\hline
\end{tabular}

Nota. $M=$ Media. $D E=$ Desviación Estándar. $\mathrm{a}=$ diferencias significativas con respecto a las imágenes apetitivas; $b=$ diferencias significativas con respecto a las imágenes neutrales; $\mathrm{c}=$ diferencias significativas con respecto a las imágenes aversivas.

\section{Discusión}

El objetivo del presente estudio fue analizar los procesos atencionales, emocionales y motivacionales a través de las respuestas psicofisiológicas de inhibición prepulso, desaceleración de la tasa cardiaca, respuesta de conductividad de la piel y modulación afectiva del reflejo de sobresalto ante estímulos apetitivos, neutrales y aversivos, e identificar las posibles diferencias entre hombres y mujeres. Los resultados muestran que los estímulos afectivos (i. e. apetitivos y aversivos) generan una mayor respuesta atencional, lo que se observa en la mayor desaceleración de la tasa cardiaca y la mayor inhibición prepulso en comparación con las imágenes neutrales. También se observó una mayor activación simpática (i. e. RCP) ante estímulos afectivos en comparación con los estímulos neutrales y se identificó el fenómeno de modulación afectiva del reflejo de sobresalto donde las imágenes aversivas lo potenciaron y las apetitivas lo inhibieron. Se resalta la ausencia de diferencias significativas entre hombres y mujeres en todas las medidas fisiológicas y subjetivas.

La mayor RCP ante estímulos afectivos es un claro indicador de mayor actividad del sistema nervioso simpático ante estos tipos de estímulos, en comparación con los neutrales. Estos resultados corroboran el modelo bioinformacional de las emociones (Lang, 1995), 
donde el arousal está en función de la valencia, generándose una mayor actividad simpática tanto ante la estimulación apetitiva como ante la defensiva, debido a que en ambos casos se requiere la inversión de energía para generar conductas de aproximación o evitación, respectivamente (Bradley \& Lang, 2007). La RCP también es un indicador de una respuesta de orientación (Bradley, 2009), lo que sugiere que los estímulos afectivos generan mayor respuesta de orientación que los estímulos neutrales.

La mayor desaceleración de la tasa cardiaca como indicador fisiológico de una respuesta de atención hacia estímulos afectivos es coherente con los resultados en la RCP y ha sido observada previamente en diferentes estudios (Bradley, 2009; Bradley et al., 2001). La activación progresiva del sistema motivacional apetitivo o defensivo implica el cambio de una fase inicial de atención a una fase final de acción (Bradley \& Lang, 2007), de esta forma, los estímulos altamente apetitivos o aversivos se asocian a una mayor desaceleración de la tasa cardiaca. La respuesta de bradicardia o desaceleración de la tasa cardiaca ante estímulos novedosos se ha observado en toda clase de animales, desde reptiles hasta mamíferos, y está controlada por la inervación parasimpática vagal, a través de receptores colinérgicos del corazón (Lang, Simons, \& Balaban, 2013). La función evolutiva de la respuesta de bradicardia es facilitar el procesamiento central de la información sensorial presente en el contexto a través de la redistribución del fluido sanguíneo (Graham \& Clifton, 1966).

Los resultados con la metodología de inhibición prepulso también muestran una mayor respuesta atencional ante las imágenes con contenido afectivo (apetitivas y aversivas) en comparación con las imágenes neutrales, lo que se observa en la inhibición del reflejo de sobresalto ante las imágenes afectivas. Estos mismos resultados han sido encontrados previamente (Bradley et al., 2006), y sugieren que los estímulos afectivos capturan mayores recursos atencionales de forma inmediata y dejan pocos recursos para otros estímulos (sonido de sobresalto); por el contrario, las imágenes neutrales, al ser poco relevantes, capturan pocos recursos atencionales y dejan muchos recursos libres, los cuales son invertidos en el sonido, generando, de esta forma, una mayor amplitud del reflejo de sobresalto. Otros estudios han obtenido resultados contradictorios; Gard, Gard, Mehta, Kring y Patrick (2007) encontraron una potenciación del reflejo de sobresalto ante imágenes aversivas aun ante una corta latencia entre la imagen y el sonido, estos resultados sugieren que cuando el estímulo aversivo es altamente relevante para el individuo (relevancia conductual), logra activar el sistema motivacional defensivo en pocos milisegundos, por ejemplo, con personas fóbicas (Globisch, Hamm, Esteves, \& Öhman, 1999).

Finalmente, se observó el patrón de modulación afectiva del reflejo de sobresalto a partir de la valencia de los estímulos. Estos resultados han sido reportados previamente (Gantiva et al., 2015; Lang, 1995) e indican que los reflejos defensivos pueden ser utilizados como indicadores confiables de la valencia experimentada ante un estímulo o contexto particular. La potenciación del reflejo de sobresalto ante estímulos aversivos ocurre por la correspondencia entre la valencia del estímulo sonoro que genera el reflejo de sobresalto y el estímulo que se está observando (i. e. ambos son aversivos), por el contrario la inhibición del reflejo ante estímulos apetitivos ocurre porque no existe correspondencia entre las valencias, generando una resta en la valencia aversiva del estímulo sonoro que genera el sobresalto (Gantiva et al., 2015). Esta metodología ha sido ampliamente utilizada como indicador objetivo de la respuesta afectiva ante diferentes tipos de estímulos (p. ej., Duval, Lovelace, Aarant, \& Filion, 2013; Muñoz, Idrissi, Sánchez-Barrera, Fernández, \& Vila, 2011) y poblaciones (Grillon $\&$ Baas, 2003).

En conjunto, nuestros resultados sugieren que este tipo de metodologías para el estudio de la emoción, la atención y la motivación son efectivas y pueden ser utilizadas en diferentes contextos o en distintos campos, como por ejemplo, los cambios que ocurren después de la terapia, la comprensión de los distintos procesos 
psicológicos en personas con algún trastorno ante estímulos relacionados con su problemática, la psicología del consumidor y la psicología social, entre otros. Con respecto al uso de estas herramientas en hombres y mujeres, nuestros resultados no muestran ninguna diferencia en las medidas fisiológicas y subjetivas, sin embargo, otros estudios sí han mostrado diferencias (Bradley, Codispoti, Sabatinelli, \& Lang, 2001), esto ocurre porque los estímulos utilizados en cada estudio no fueron los mismos, por lo cual los resultados no son comparables entre poblaciones. Sin embargo, las diferencias entre sexos no van dirigidas hacia respuestas diferentes entre hombres y mujeres, sino a la intensidad de las respuestas.

Los resultados encontrados deben ser analizados teniendo en cuenta algunas limitaciones. Primero, los puntajes en arousal de las imágenes aversivas fueron menores a lo esperado, esto explica porque la RCP y la desaceleración de la tasa cardiaca no fueron mayores ante las imágenes aversivas, lo que ha sido encontrado en otras investigaciones (Bradley et al., 2001), sin embargo, este elemento no altera las conclusiones del estudio, dado que las diferencias en las respuestas de atención (desaceleración de la tasa cardiaca e inhibición prepulso) y arousal (RCP) se presentan ante estímulos afectivos versus estímulos neutrales (Bradley, 2009). Segundo, se sugiere, para futuros estudios, aumentar cada vez más el número de respuestas fisiológicas como indicadores de respuestas psicológicas para fortalecer metodológicamente las investigaciones en el campo de la psicología, por ejemplo, la actividad del músculo corrugador, cigomático y orbicular.

\section{Agradecimientos}

Este estudio fue financiado por la Universidad de San Buenaventura, Bogotá (Ref. CHS 011-015).

\section{Referencias}

Blumenthal, T. D., Cuthbert, B. N., Filion, D. L., Hackley, S., Lipp, O. V., \& van Boxtel, A. (2005). Committee report: Guidelines for human startle eyeblink electromyographic studies. Psychophysiology, 42, 1-15. https://d oi.org/10.1111/j.1469-8986.2005.00271.x

Bradley, M. (2009). Natural selective attention: Orienting and emotion. Psychophysiology, 46, 1-11. https://doi.org/10.1111/j.1469-89 86.2008.00702.x

Bradley, M. M., Codispoti, M., Cuthbert, B., \& Lang, P. J. (2001). Emotion and motivation I: Defensive and appetitive reactions in picture processing. Emotion, 1(3), 276-298. https://doi.org/10.1037//152 8-3542.1.3.276

Bradley, M. M., Codispoti, M., \& Lang, P. J. (2006). A multi-process account of startle modulation during affective perception. Psychophysiology, 43(5), 486-497. https://do i.org/10.1111/j.1469-8986.2006.00412.x

Bradley, M. M., Codispoti, M., Sabatinelli, D., \& Lang, P. J. (2001). Emotion and motivation II: Sex differences in picture processing. Emotion, 1(3), 300-319. https://doi.org/10.1 037//1528-3542.1.3.300

Bradley, M. M., Cuthbert, B. N., \& Lang, P. J. (1993). Pictures as prepulse: Attention and emotion in startle modification. Psychophysiology, 30(5), 541-545. https://do i.org/10.1111/j.1469-8986.1993.tb02079.x

Bradley, M. M., \& Lang, P. J. (1994). Measuring emotion: The self-assessment manikin and the semantic differential. Journal of Behavior Therapy and Experimental Psychiatry, 25(1), 49-59. https://doi.org/10.1016/0005-7916( 94) $90063-9$

Bradley, M. M., \& Lang, P. J. (2007). Emotion and motivation. En J. Cacioppo, L. Tassinary \& G. Berntson (Eds.), The handbook of psychophysiology (3.a ed., pp. 581-607). Nueva York: Cambridge University Press.

Cohen, J. (1988). Statistical power analysis for the behavioral sciences (2.a ed.). Hillsdale, NJ: Lawrence Erlbaum. 
Duval, E. R., Lovelace, C. T., Aarant, J., \& Filion, D. L. (2013). The time course of face processing: Startle eyeblink response modulation by face gender and expression. International Journal of Psychophysiology, 90(3), 354-357. https://doi.org/10.1016/j.ij psycho.2013.08.006

Faul, F., Erdfelder, E., Lang, A., \& Buchner, A. (2007). G*Power 3: A flexible statistical power analysis program for the social, behavioral, and biomedical sciences. Behavior Research Methods, 39, 175-191. ht tps://doi.org/10.3758/BF03193146t

Gantiva, C., Araujo, A., Aragão, N., \& Hewitt, N. (2017). Modulation of physiological responses as indices of attentional bias in Dysphoria. International Journal of Mental Health and Addiction, 16(2), 328-338. https ://doi.org/10.1007/s11469-017-9774-7

Gantiva, C., \& Camacho, K. (2016). Características de la respuesta emocional generada por las palabras: un estudio experimental desde la emoción y la motivación. Psychologia. Avances de la Disciplina, 10(2), 55-62. https://doi.org/10. 21500/19002386.2550

Gantiva, C., Delgado, R., \& Romo-González, T. (2015). Emotional reactions to alcoholrelated words: Differences between lowand high-risk drinkers. Addictive Behaviors 50, 60-63. https://doi.org/10.1016/j.addbeh .2015 .06 .004

Gantiva, C., Estupiñan, E., Montaña, I., Sierra, M., Zocadegui, E., \& Romo-González, T. (2014). Emotional dimensions in people with aggressive behavior: Differential responses to affective visual stimuli. Trends in Psychiatry and Psychotherapy, 36(4), 203-208. https://doi.org/10.1590/2237-608 9-2014-0004

Gantiva, C., Guerra, P., \& Vila, J. (2011). Validación colombiana del sistema internacional de imágenes afectivas: evidencias del origen transcultural de la emoción. Acta Colombiana de Psicología, 14(2), 103-111. Recuperado de http://psyc net.apa.org/record/2012-13271-009
Gantiva, C., Guerra, P., \& Vila, J. (2015). Modulación del reflejo de sobresalto en población colombiana: evidencia de la interacción entre emoción y motivación. Universitas Psychologica, 14(1), 157-164. https://doi.org/10.11144/Javerian a.upsy14-1.mrsp

Gantiva, C., Rodríguez, M., Arias, M., \& Rubio, E. (2012). Dimensiones de la emoción durante el proceso de abandono del consumo de tabaco: un apoyo a la visión motivacional del cambio. Diversitas: Perspectivas en Psicología, 8(2), 309-317. https://doi.org/10.15332/s1794-9 998.2012.0002.07

Gard, D. E., Gard, M. G., Mehta, N., Kring, A. M., \& Patrick, C. J. (2007). Impact of motivational salience on affect modulated startle at early and late probe times. International Journal of Psychophysiology, 66(3), 266-270. https://doi.org/10.1016/j.ij psycho.2007.05.005

Globisch, J., Hamm, A. O., Esteves, F., \& Öhman, A. (1999). Fear appears fast: Temporal course of startle reflex potentiation in animal fearful subjects. Psychophysiology, 36(1), 66-75. https://doi.org/10.1017/S004 8577299970634

Graham, F. K., \& Clifton, R. K. (1966). Heart-rate change as a component of the orienting response. Psychological Bulletin, 65(5), 305-320. https://doi.org/10.1037/h0 023258

Grillon, C., \& Baas, J. (2003). A review of the modulation of the startle reflex by affective states and its application in psychiatry. Clinical Neurophysiology, 114(9), 1557-1579. https://doi.org/10.1016/S13882457(03)00202-5

Hamm, A. O., Cuthbert, B. N., Globisch, J., \& Vaitl, D. (1997). Fear and the startle reflex: Blink modulation and autonomic response patterns in animal and mutilation fearful subjects. Psychophysiology, 34(1), 97-107. https://doi.org/10.1111/j.1469-898 6.1997.tb02420.x

Lang, P. J. (1995). The emotion probe: Studies of motivation and attention. American 
Psychologist, 50, 372-385. https://doi.org/10 .1037/0003-066X.50.5.372

Lang, P. J., Bradley, M., \& Cuthbert, B. (2008). International affective picture system (IAPS): Affective ratings of pictures and instruction manual (Technical Report A-8). Gainesville, FL: University of Florida.

Lang, P. J., Davis, M., \& Öhman, A. (2000). Fear and anxiety: Animal models and human cognitive psychophysiology. Journal of Affective Disorders, 61 (3), 137-159. https: //doi.org/10.1016/S0165-0327(00)00343-8

Lang, P. J., Simons, R. F., \& Balaban, M. (Eds.). (2013). Attention and orienting: Sensory and motivational processes. Nueva York: Psychology Press.

Miccoli, L., Delgado, R., Rodríguez-Ruiz, S., Guerra, P., García-Mármol, E., \& Fernández-Santaella, M. C. (2014). Meet OLAF, a good friend of the IAPS! The open library of affective foods: A tool to investigate the emotional impact of food in adolescents. PloS one, 9(12), e114515. http s://doi.org/10.1371/journal.pone.0114515

Muñoz, M., Viedma-del-Jesús, M., Rosselló, F., Sánchez-Nácher, N., Montoya, P., \& Vila, J. (2013). The emotional impact of European tobacco-warning images. Tobacco Control, 22, 123-129. https://doi.org/10.1136/tobac cocontrol-2011-050070

Muñoz, M., Idrissi, S., Sánchez-Barrera, M., Fernández, M., \& Vila, J. (2011). Motivation to quit smoking and startle modulation in female smokers: Context specificity of smoking cue reactivity. Psychopharmacology, 218, 525-532. https://d oi.org/10.1007/s00213-011-2334-0

Richardson, J. T. (2011). Eta squared and partial eta squared as measures of effect size in educational research. Educational Research Review, 6(2), 135-147. https://doi.org/10.10 16/j.edurev.2010.12.001

\section{Notas}

* Artículo de investigación.

1 Los códigos de las imágenes del IAPS fueron: 1525, 1932, 2235, 2393, 2579, 2683, 2980,
$3068,3069,3195,3213,4668,4676,4677$, 4692, 4693, 4698, 6315, 6415, 6520, 7013, 7018, 7021, 7026, 7041, 7161, 7179, 7493, 7504, 8158, 8178, 8179, 8186, 8191, 9163, 9187. 